\title{
PENGARUH VARIASI KUAT ARUS TERHADAP LEBAR PEMOTONGAN DAN KEKERASAN PADA BAJA KARBON SEDANG DENGAN CNC PLASMA ARC CUTTING
}

\author{
Riska Surya Agnitias ${ }^{1}$, Rusiyanto ${ }^{2}$ \\ 1,2,3Pendidikan Teknik Mesin, Fakultas Teknik, Universitas Negeri Semarang \\ Email: rsagnitias@gmail.com
}

\begin{abstract}
The purpose of this research is to determine the effects of current variation to the cutting kerf and hardness in medium carbon steel cutting process using CNC Plasma Arc Cutting. This research uses experiment methods to study the effect of a given treatment. The electric current were varied for 20, 25, 30, 35, and 40 amps. The test parameters were cutting kerf and hardness. The data were analyzed using descriptive statistics. The test result shows that there are differences in cutting kerf and hardness. The lowest kerf and hardness value was obtained from the 20 amps current, with a kerf of $1.64 \mathrm{~mm}$ and a hardness of $707.4 \mathrm{HV}$. The highest kerf and hardness value was obtained from the 40 amps current test, with a kerf of $2.58 \mathrm{~mm}$ and a hardness of 857.7 $H V$. This research concludes that the variation of electric current in CNC Plasma Arc Cutting process of medium carbon steel affects the kerf (99.59\%) and hardness (94.17\%).
\end{abstract}

Keywords: medium carbon steel, current variation, hardness, cut width, kerf, plasma arc cutting

\begin{abstract}
ABSTRAK
Tujuan penelitian ini adalah untuk mengetahui seberapa besar variasi kuat arus memberikan pengaruh terhadap lebar pemotongan (Kerf Width) dan kekerasan pada proses pemotongan baja karbon sedang dengan menggunakan CNC Plasma Arc Cutting. Metode yang digunakan dalam penelitian ini adalah metode eksperimen dengan tujuan untuk mengetahui pengaruh sebab akibat terhadap perlakuan yang diberikan. Variasi kuat arus yang digunakan dalam proses pemotongan ini adalah $20 \mathrm{~A}, 25 \mathrm{~A}$, 30A, 35A, dan 40A. Pengujian yang di lakukan adalah kekerasan dan lebar pemotongan (Kerf Width). Data yang diperoleh kemudian dianalisis menggunakan teknik analisis statistik diskriptif. Hasil penelitian yang diperoleh menunjukkan bahwa terjadi perubahan nilai lebar pemotongan (Kerf Width) dan nilai kekerasan. Nilai lebar pemotongan (Kerf Width) dan kekerasan terendah diperoleh pada penggunaan arus sebesar 20 A yaitu dengan nilai lebar sebesar 1,64 mm dan kekerasan sebesar 707,4 HV. Nilai lebar pemotongan (Kerf Width) dan kekerasan tertinggi diperoleh pada penggunaan arus sebesar 40A dengan nilai lebar 2,58 mm dan kekerasan sebesar 857,7 HV. Penelitian ini dapat disimpulakan bahwa variasi kuat arus pada proses pemotongan baja karbon sedang menggunakan CNC Plasma Arc Cutting memberi pengaruh sebesar 99,59\% terhadap nilai lebar pemotongan (Kerf Width) dan sebesar $94,17 \%$ terhadap nilai kekerasan.
\end{abstract}

Kata Kunci: Baja Karbon Sedang, Variasi Kuat Arus, Kekerasan, Lebar Pemotongan (Kerf Width), Plasma Arc Cutting

\section{PENDAHULUAN}

Terdapat beberapa metode yang dapat digunakan pada pemotongan sebuah material. Pemotongan pertama menggunakan tenaga mekanis yaitu pengguntingan dan penggerajian, dan kedua adalah pemotongan dengan menggunakan sumber panas bertemperatur tinggi. Pemotongan ini menggunakan gas atau dengan busur plasma (Sunaryo, 2008: 51).

Salah satu proses pemotongan yang memberikan efisiensi waktu dalam pengerjaan ialah proses pemotongan logam dengan menggunakan busur plasma atau plasma arc 
cutting. Proses pemotongan menggunakan plasma arc cutting tidak membutuhkan waktu pemanassan awal sehingga menjadikan proses pemotongan menjadi lebih cepat. Waktu merupakan hal yang diperhitungkan di dalam dunia kerja. Menurut Suwasono dalam Hamid et al, (2018: 13). "Kebutuhan jam orang (JO) untuk paket kerja masuk kedalam anggaran. Apabila suatu paket kerja tidak lengkap dan ketika anggaran telah habis, maka akan ada kecenderungan untuk meminjam jam orang dari suatu pekerjaan lain yang melebihi anggaran"

Pemotongan busur plasma merupakan proses yang banyak digunakan untuk pemotongan logam. Proses pemotongan tersebut menggunakan gas yang terionisasi atau biasa disebut dengan plasma yang ditekan keluar dengan kecepatan tinggi menggunakan torch plasma (Singh, 2011). Proses pemotongan busur plasma dapat digunakan untuk melakukan pemotongan logam yang memiliki konduktivitas listrik. Salah satu jenis material logam yang memiliki konduktivitas listrik ialah baja karbon sedang. Menurut (Suarsana, 2017: 33) baja karbon sedang merupakan baja dengan kandungan karbon sebesar 0,25 - 0,55\%. Proses pemotongan diawali dengan terbentuknya busur api diantara elektroda dan benda kerja dari hasil reaksi ionisasi listrik terhadap gas potong. Gas tersebut dipanaskan oleh busur api sehingga suhunya meningkat dan kemudian gas akan terionisasi menjadi penghantar listrik. Gas yang terionisasi dalam kondisi ini disebut plasma. Plasma dialirkan melalui nozzle untuk memotong benda kerja (Akhmad, 2009).

Parameter yang mempengaruhi kualitas hasil pemotongan material dan waktu pengerjaan menggunakan busur plasma adalah: kecepatan pemotongan, kuat arus, ketinggian torch terhadap permukaan potong, tekanan gas dan aliran gas plasma (Salonitis \& Vatousianos, 2012). Salah satu parameter yang berpengaruh pada pemotongan dengan menggunakan plasma arc cutting adalah kuat arus. Kuat arus merupakan parameter yang secara langsung mempengaruhi penembusan dan kecepatan pencairan logam. Apabila kuat arus yang digunakan semakin tinggi maka suhu pada busur plasma meningkat yang membuat proses pemotongan akan menjadi lebih cepat (Jeffus, 2012: 539). Energi panas yang sangat terfokus pada saat pemotongan logam dengan menggunakan plasma arc cutting dapat meningkatkan nilai dari lebar pemotongan dan terjadinya perubahan pada kekerasan material logam. Pengaruh lebar pemotongan dan kekerasan pada proses pemotongan dengan menggunakan plasma arc cutting memberikan kerugian karena, apabila lebar pemotongan terlalu besar maka material yang terbuang akan meningkat. Peningkatan material terbuang menyebabkan ketelitian ukuran hasil pemotongan menurun sehingga hasil pemotongan menjadi tidak sesuai dengan desain atau gambar. Perubahan kekerasan pada material hasil potong akan menyebabkan lamanya proses untuk dilakukan langkah kerja selanjutnya. Apabila salah satu proses produksi terhambat maka akan menyebabkan menurunnya hasil produksi yang akan menyebabkan kerugian.

\section{METODE}

Metode penelitian yang digunakan pada penelitian ini adalah metode eksperimen. Penelitian eksperimen adalah metode yang digunakan untuk mencari pengaruh tertentu terhadap yang lain dalam kondisi yang terkendalikan (Sugiyono, 2015: 108). Data yang diperoleh kemudian di analisis menggunakan analisis statistik deskriptif. Statistik deskriptif ialah statistik yang digunakan untuk menganalisis data dengan cara mendeskripsikan atau menggambarkan data yang telah terkumpul sebagaimana adanya tanpa bermaksud membuat kesimpulan untuk umum atau generalisasi (Sugiyono, 2015: 207).

Variabel bebas dalam penelitian ini adalah kuat arus dengan variasi sebesar $20 \mathrm{~A}$, 25A, 30A, 35A, dan 40A. Penggunaan variasi arus untuk mendapatkan hasil pemotongan yang optimal dengan variabel terikat berupa lebar pemotongan (kerf width) dan nilai kekerasan. 
Alat yang digunakan dalam penelitian berupa: mesin plasma arc cutting Redbo Cut40, mesin penggerak, alat uji micro hardness test Vickers, vernier caliper. Bahan yang digunakan sebagai penelitian adalah baja karbon sedang dengan kandungan karbon sebesar $0,51 \%$.

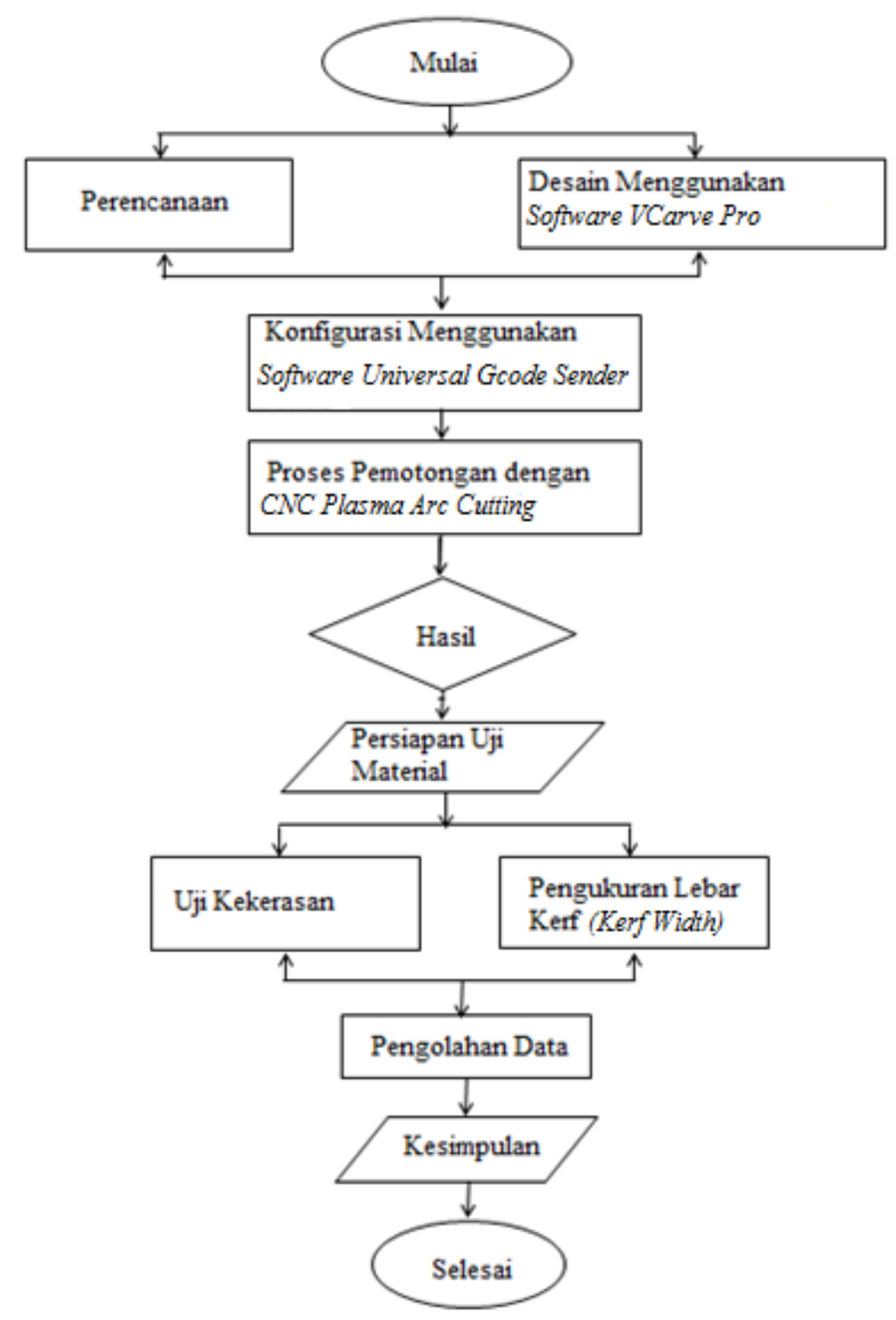

Gambar 1. Diagram Alir Penelitian

\section{HASIL DAN PEMBAHASAN}

Pengukuran lebar pemotongan menggunakan alat vernier caliper. Lebar pemtongan diukur sebagai rata-rata lebar pemotongan atas dan lebar pemotongan bawah dari potongan lubang yang dibuat pada setiap spesimen. Pengujian kekerasan dilakukan dengan mengambil 3 titik uji secara acak untuk memperoleh data pengujian. Hasil pengukuran lebar pemotongan dan kekerasan dengan variasi arus dapat dilihat pada Tabel 1. 
Tabel 1. Hasil Pengukuran

\begin{tabular}{|c|c|c|c|}
\hline \multirow[b]{2}{*}{ No } & \multirow[b]{2}{*}{$\begin{array}{l}\text { Kuat Arus } \\
\text { (A) }\end{array}$} & \multicolumn{2}{|c|}{ Pengujian } \\
\hline & & Lebar pemotongan (mm) & $\begin{array}{l}\text { Kekerasan } \\
(\mathrm{HV})\end{array}$ \\
\hline 1 & 20 & 1,64 & 707,4 \\
\hline 2 & 25 & 1,83 & 710,7 \\
\hline 3 & 30 & 2,07 & 792,4 \\
\hline 4 & 35 & 2,30 & 818,4 \\
\hline 5 & 40 & 2,58 & 857,7 \\
\hline
\end{tabular}

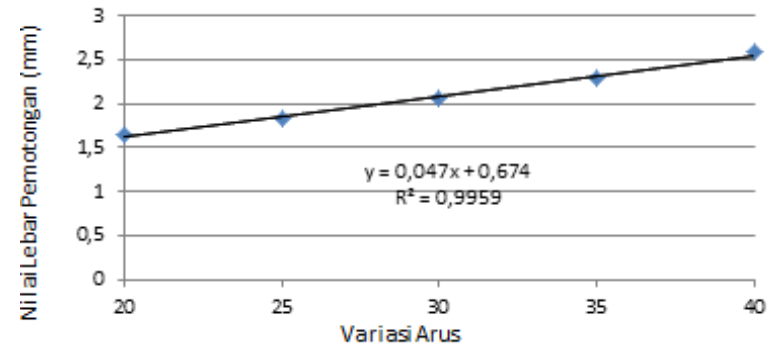

Gambar 2. Hasil Pengujian Lebar Pemotongan

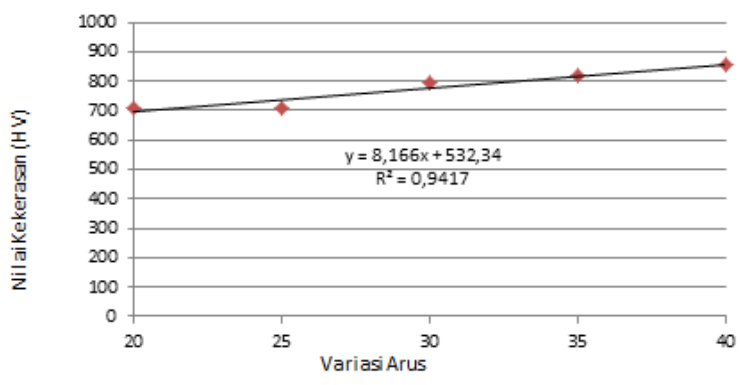

Gambar 3. Hasil Pengujian Kekerasan

Hasil Pengukuran Lebar Pemotongan. Lebar pemotongan merupakan celah yang dihasilkan dari sebuah proses pemotongan. Tujuan dilakukanya pengukuran lebar pemotongan adalah untuk mengetahui seberapa besar material yang hilang akibat dari proses pemotongan dengan menggunakan $C N C$ Plasma Arc Cutting. Lebar pemotongan memberi pengaruh terhadap tingkat ketelitian ukuran pada setiap hasil pemotongan.

Penelitian ini menunjukkan bahwa variasi kuat arus mempengaruhi nilai lebar pemotongan. Kuat arus sebesar 20 A memberikan pengaruh terhadap nilai lebar pemotongan sebesar $1,64 \mathrm{~mm}$ dan pada arus 40 A didapat nilai lebar pemotongan tertinggi sebesar 2,58 mm. Kenaikan nilai lebar pemotongan dapat dilihat pada Gambar 2.
Kenaikan tersebut disebabkan karena meningkatnya kuat arus menyebabkan meningkatnya daya plasma sehingga membuat nyala plasma menjadi semakin besar dan menyebabkan turbulensi yang lebih besar pada daerah pelelehan atau daerah potong (Masoudi, et al. 2018: 6). Apabila nyala plasma menjadi semakin besar akan menyebabkan nilai dari lebar pemotongan semakin meningkat. Namun peningkatan arus juga menyebabkan hasil potong menjadi lebih tidak beraturan karena turbulensi yang lebih besar pada daerah pelelehan atau daerah potong menyebabkan puncak dan lembah yang lebih besar. Penelitian ini diperkuat oleh penelitian yang dilakukan oleh Hamid, (2014) mengenai Variasi Kuat Arus dan Gas Flow Rate terhadap Lebar Kerf pada Pemotongan Aluminium 5083 menggunakan Mesin Cutting Plasma, dimana hasil penelitian tersebut menunjukkan bahwa semakin tinggi kuat arus maka lebar kerf yang dihasilkan menjadi semakin lebar. Kemudian diperkuat dengan penelitian yang dilakukan oleh Peko, et al (2018) mengenai modelling of kerf width in plasma jet metal cutting process using ANN approach, dimana hasil penelitian tersebut menunjukkan perbedaan lebar pemotongan akibat parameter pemotongan (ketinggian potong, kecepatan pemotongan, dan kuat arus).

Hasil Uji Kekerasan. Pengujian kekerasan bertujuan untuk mengetahui kekuatan suatu material terhadap tekanan yang dapat diterimanya. Pengujian kekerasan pada penelitian ini dilakukan dengan menggunakan alat uji kekerasan mikro vickers dengan pembebanan 300 gf selama 10 s. Pengujian kekerasan dilakukan pada daerah heat affected zone.

Kenaikan nilai kekerasan ditunjukkan pada Gambar 3. Nilai kekerasan terendah diperoleh pada penggunaan arus sebesar $20 \mathrm{~A}$ 
dengan nilai kekerasan yaitu 707,4 HV. Nilai kekerasan tertinggi diperoleh pada penggunaan arus sebesar 40 A dengan nilai kekerasan yaitu 857,7 HV. Perubahan kekerasan terjadi karena meningkatnya kuat arus menyebabkan meningkatnya daya plasma dan suhu pada busur plasma. Apabila terjadi peningkatan suhu maka akan menyebabkan terjadinya perubahan struktur pada logam baja. Berdasarkan diagram fasa $\mathrm{Fe}_{3} \mathrm{C}$, perubahan struktur fasa pada baja karbon sedang dengan kandungan karbon sebanyak $0,51 \%$ terjadi pada suhu $727^{\circ} \mathrm{C}$ sedangkan suhu dari busur plasma yaitu berkisar antara $2000^{\circ}-3000^{\circ} \mathrm{C}$. Penelitian ini sejalan dengan penelitian yang dilakukan oleh Çelik, (2013) mengenai Investigating the Effects of Cutting Parameters on Material Cut in CNC Plasma. Perubahan fasa pada sebuah material menyebabkan perubahan pada sifat mekanik suatu material. Perubahan tersebut akan menjadi sebuah kerugian karena material hasil potong menjadi lebih keras, sehingga akan memerlukan banyak waktu untuk dilakukan proses finishing.

\section{SIMPULAN}

Hasil sajian data dan pembahasan menunjukkan bahwa 1) Variasi arus terhadap nilai dari lebar pemotongan sebesar 99,59\%. Nilai lebar pemotongan terendah didapatkan pada penggunaan arus $20 \mathrm{~A}$ dengan nilai lebar pemotongan 1,64 $\mathrm{mm}$ dan nilai lebar terbesar didapatkan pada penggunaan arus $40 \mathrm{~A}$ dengan nilai lebar pemotongan sebesar 2,58 mm. Dapat disimpulkan apabila arus dalam pemotongan menggunakan cnc plasma arc cutting yang digunakan semakin tinggi maka akan menghasilkan nilai lebar pemotongan yang semakin besar 2) Variasi arus pada nilai kekerasan di daerah HAZ terhadap material baja karbon sedang. Berdasarkan data nilai kekerasan pada daerah HAZ menggunakan arus yang telah ditentukan, dapat disimpulkan bahwa arus memberikan pengaruh terhadap nilai kekerasan sebesar $94,17 \%$. Nilai kekerasan material sebelum dilakukan pemotongan yaitu sebesar 232,9 HV namun setelah dilakukan pemotongan terjadi perubahan nilai kekerasan. Nilai kekerasan terendah diperoleh pada penggunaan arus $20 \mathrm{~A}$ yaitu sebesar 707,4 HV dan nilai kekerasan tertinggi pada arus 40 A dengan nilai kekerasan sebesar 857,7 HV.

\section{DAFTAR RUJUKAN}

Akhmad, A.A. 2009. "Pemesinan non konvensional plasma arc cutting". Jurnal Rekayasa Mesin, 9(2), 51-56.

Çelik, Y.H. 2013. "Investigating the Effects of Cutting Parameters on Materials Cut in CNC plasma". Materials and Manufacturing Process, Vol 28: 1053-1060

Hamid, A. 2014. "Variasi Kuat Arus dan Gas Flow Rate terhadap Lebar Kerf pada Pemotongan Aluminium 5083 Menggunakan Cutting Plasma". Fakultas Teknik. Universitas Negeri Malang.

Hamid, A., Oyong N., Teguh D.W. 2018. "Optimasi Proses Parameter Pemotongan Plasma Arc Cutting pada Logam Aluminium Menggunakan Metode Taguchi" Prosiding SNST 9. Fakultas Teknik Universitas Wahid Hasyim. Semarang. 13-18

Jeffus, L. 2012. Welding Principles and Applications $7^{\text {th }}$ ed. US: Cengage Learning.

Masoudi, S., et al. 2018. "Development of an intelligent model to optimize heataffected zone, kerf, and roughness in 309 stainless steel plasma cutting by using experimental results". Materials and Manufacturing Processes. https://doi.org/10.1080/10426914.201 8.1532579

Peko, I, Bogdan N., Aleksandar D, and Ivica V. 2018. "Modelling of Kerf Width in Plasma Jet Metal Cutting Process using ANN Approach" Tehnicki vjesnik Vol. 25(2) : 401-406. https://doi.org/10.17559/TV$\underline{20161024093323}$ 
Salonitis, K., \& Vatousianos, S. 2012. "Experimental investigation of the plasma arc cutting process". Procedia CIRP Vol. 3(1) : 287-292. https://doi.org/10.1016/j.procir.2012.0 $\underline{7.050}$

Singh, Vivek. 2011. "Analysis of Process Parameters of Plasma Arc Cutting using Design of Experiment”. Departemen of Mechanical Engineering, National Institute of Technology Rourkela. Thesis.
Suarsana. 2017. Diktat Ilmu Material Teknik. Denpasar: Universitas Udayana.

Sugiyono. 2013. Metode Penelitian Kuantitatif, Kualitatif, dan $R \& D$. Bandung: Alfabeta.

Sunaryo, H. 2008. Teknik Pengelasan Kapal Jilid 1. Jakarta: Direktorat Pembinaan Sekolah Menengah Kejuruan. 